\title{
Canine Trichomonas tenax mandibular gland infestation
}

\author{
Klaudiusz Szczepaniak ${ }^{1 *}$, Anna Łojszczyk-Szczepaniak², Krzysztof Tomczuk' ${ }^{1}$ Tomasz Skrzypek ${ }^{3}$, Barbara Lisiak ${ }^{2}$ \\ and Zahrai Abd-Al-Hammza Abbass ${ }^{1}$
}

\begin{abstract}
Background: Several species of trichomonads are intestinal or urogenital parasites of humans and animals, with only a few species typically being located in the oral cavity. The prevalence of oral trichomoniasis in dogs is approximately $15-25 \%$, although the prevalence varies among different populations and depends on age, sex and the health of the oral cavity.

Case presentation: A case of mandibular gland infestation by trichomonads in a 13-year-old female Dachshund with advanced periodontal disease and oral trichomoniasis is reported. The dog was referred due to a history of a painless swelling over the left submandibular region that increased in size over time. Based on physical and ultrasound examinations, a final diagnosis of mandibular gland cyst was established and transcutaneous needle aspiration was carried out. Numerous mobile trophozoites of trichomonads were found by microscopy and culturing for trichomonas was performed. The species was finally characterized as Trichomonas tenax by polymerase chain reaction and sequencing.

Conclusions: Studies have shown that T. tenax can be found in humans in atypical locations such as the salivary glands and upper and lower respiratory tracts. According to our knowledge this is the first report of T. tenax being present in the salivary glands of a dog. Because of the relatively high prevalence of trichomoniasis in dogs with periodontal diseases, these parasites should be considered together with bacterial and viral agents in salivary gland infections, especially in individuals with compromised oral health.
\end{abstract}

Keywords: Dog, Trichomonads, Salivary gland, Sialocele

\section{Background}

Trichomonadea, commonly known as trichomonads, comprises a class of amitochondriate flagellated protists belonging to the phylum Parabasalia. They are morphologically characterized by multiple anterior flagella and a single recurrent flagellum that functions as support for the undulating membrane [1]. Several species are considered to be intestinal or urogenital parasites of humans and animals. Only a few species are typically present in the oral cavity of animals [2] and to date, oral infestation caused by trichomonads in domestic carnivores

\footnotetext{
*Correspondence: k.o.szczepaniak@gmail.com

${ }^{1}$ Department of Parasitology and Invasive Diseases, Faculty of Veterinary Medicine, University of Life Sciences in Lublin, at Ul. Akademicka 12, 20-033 Lublin, Poland

Full list of author information is available at the end of the article
}

have been reported rarely. The first report on oral trichomoniasis in dogs was done by Hegner and Ratcliffe [3], who described the species Trichomonas canistomae. Later, oral trichomoniasis was recorded by Beelitz et al. [4] and Breuker [5]. Recently, polymerase chain reaction (PCR) based molecular characterization of the various trichomonad species isolated from the oral cavity of dogs (mostly from Europe) confirmed the presence of Trichomonas tenax, Trichomonas canistomae and other Trichomonas sp., [6-9]. The prevalence of oral trichomoniasis in dogs is approximately $15-25 \%$, although the prevalence varies in different populations depending on age, sex and the clinical condition of the oral cavity $[4,5,8]$.

Here we report the infestation of a salivary gland by $T$. tenax in a 13-year-old dog having advanced periodontal disease.

\section{Biomed Central}

(c) 2016 Szczepaniak et al. This article is distributed under the terms of the Creative Commons Attribution 4.0 International License (http://creativecommons.org/licenses/by/4.0/), which permits unrestricted use, distribution, and reproduction in any medium, provided you give appropriate credit to the original author(s) and the source, provide a link to the Creative Commons license, and indicate if changes were made. The Creative Commons Public Domain Dedication waiver (http://creativecommons. org/publicdomain/zero/1.0/) applies to the data made available in this article, unless otherwise stated. 


\section{Case presentation}

A 13-year-old female Dachshund was presented to the veterinary clinic at the University of Life Sciences in Lublin, Poland with a history of a soft painless oval-shaped swelling over the left side of the submandibular area that had gradually increased in size over time (Fig. 1a). The overlying skin was normal and there was no history of trauma or previous surgery in this region. Regional lymphadenopathy was not detected by palpation. According to the owner, the dog had suffered from persistent halitosis due to chronic periodontitis for several years. The dog had been treated with antibiotics or received enhanced treatment for periodontitis such as instrumental debridement and ultrasonic scaling several times during this period. An intraoral examination confirmed the existence of numerous lesions of the oral mucosa and advanced periodontal disease (Fig. 1b).

An ultrasound examination of the neck region was performed with the use of a linear $7.5 \mathrm{MHz}$ transducer. The examination revealed the presence of an anechogenic cystic lesion in the left mandibular salivary gland measuring approximately $2.5 \times 1.3 \mathrm{~cm}$. Normal mandibular tissue was only partially visible. Changes were not observed in the right mandibular gland or in other neck tissues, including the lymph nodes, which were oval in shape and hypoechoic to the adjacent tissue.

Next, abdominal and thorax radiography was performed in dorsoventral and lateral recumbency, as well as abdominal ultrasonographic examination. These examinations did not reveal any significant changes. Based on the history and the physical and ultrasound examinations, a preliminary diagnosis of a mandibular gland cyst was established.

Transcutaneous needle aspiration of the left mandibular gland was carried out and a saliva-like fluid obtained. Microscopic evaluation of fluid revealed numerous, mobile trophozoites of trichomonads, mucus and aggregation of eosinophils. Swabs were also taken from gingival pockets and revealed the presence of trichomonads and a mixed bacterial flora.

The aspirated fluid was examined bacteriologically for aerobic and anaerobic growth and for yeast cultures but was found to be without growth.

The aspirated cystic content as well as swabs from gingival pockets were inoculated on a diphasic medium for cultivation of trichomonads: solid phase composition: $9 \mathrm{ml}$ heat-inactivated horse serum, $1 \mathrm{ml} 3 \%$ beef extract, and $0.2 \mathrm{~g}$ glucose; liquid phase composition: $0.59 \mathrm{~g} \mathrm{Na}_{2} \mathrm{HPO}_{4}, 0.45 \mathrm{~g} \mathrm{KH}_{2} \mathrm{PO}_{4}, 8.0 \mathrm{~g} \mathrm{NaCl}$, dissolved in $1000 \mathrm{ml}$ distilled water. The complete medium was allocated in sterile $10 \mathrm{ml}$ tubes, supplemented with rice starch and $0.5 \mathrm{ml}$ heat-inactivated horse serum. The media were cultivated at $37^{\circ} \mathrm{C}$ and examined under light microscope every $24 \mathrm{~h}$. Positive cultures were used for morphological characterization based on scanning electron microscopy. Trophozoites were prepared according to standard procedure for protozoa cells modified according to Szczepaniak [8]. In brief, trichomonads were isolated by centrifugation $2500 \times g$ for $5 \mathrm{~min}$ and fixed with $2.5 \%$ glutaraldehyde in $0.1 \mathrm{M}$ cacodylate buffer $\mathrm{pH}$ 7.2 for $2.5 \mathrm{~h}$. Afterwards, the trichomonads were washed in phosphate-buffer saline and allowed to adhere to glass coverslips precoated with $0.1 \%$ poly-L-lysine and postfixed for $2 \mathrm{~h}$ with $1 \%$ OsO4. Fixed samples were dehydrated in ethanol and acetone, dried in a critical point using a Polaron CPD 7501 critical-point dryer and coated with gold/palladium (Au/Pd) in a Polaron Range SC7620 sputter coater. Examinations were carried out using a ZEISS Ultra Plus scanning electron microscope.

Periodontal pocket swabs showed significant growth of trichomonads in the xenic culture in contrast to the cyst aspirate, which showed slow and poor growth.
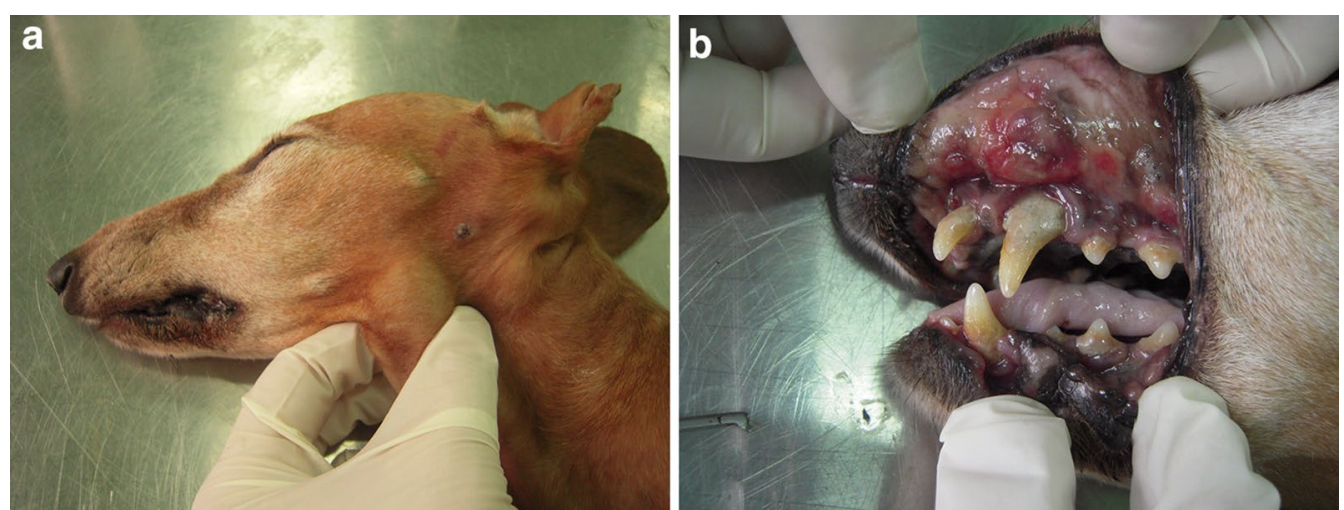

Fig. 1 Clinical findings in a case of Trichomonas tenax infestation. a Swelling of the submandibular area. b Periodontitis and lesions of the oral mucosa 
Undoubtedly, there are factors, which may influence the growth of trichomonads in vitro, such as low numbers of cells in the inoculum; but in the present study many trophozoites were found by direct microscopy of the aspirate. Because the aspirate was negative for bacteria and fungi, we hypothesise that the growth of trichomonads from the aspirate was compromised by the lack of bacteria. While some trichomonads such a $T$. vaginalis can be established directly into axenic cultures, others species (especially from alimentary track) require adaptation in monoxenic or polyxenic cultures, which is usually time consuming and laborious process $[10,11]$.

Observation of trichomonads from a positive culture (5 days after inoculation) by light microscopy and scanning electron microscopy revealed numerous trophozoites and a single spherical, non-flagellated pseudocyst. The trophozoites varied in shape from piriform to spherical with four anterior flagella and a fifth recurrent undulating membrane and axostyle (Fig. 2). Accurate assessment of flagella size was difficult due to the large number of starch granules and bacteria. The major morphological features were typical for genera trichomonas or tetratrichomonas [12]. As detection and identification of trichomonads by conventional techniques are noticeably less reliable than PCR $[12,13]$, we chose to use molecular methods for taxonomical identification. The analyses were performed on the aspirate and the classification was based on the analysis of the partial sequence of the gene encoding in the SSU rDNA and the ITS region (ITS1, 5.8S rDNA, ITS2), after performing PCR with the primers TFR1 ( $5^{\prime}$-TGC TTC AGT TCA GCG GGT CTT $C$ - $\left.-3^{\prime}\right)$ and TFR2 (5'-CGG TAG GTG AAC CTG CCG TTG G-3') according to the protocol described by

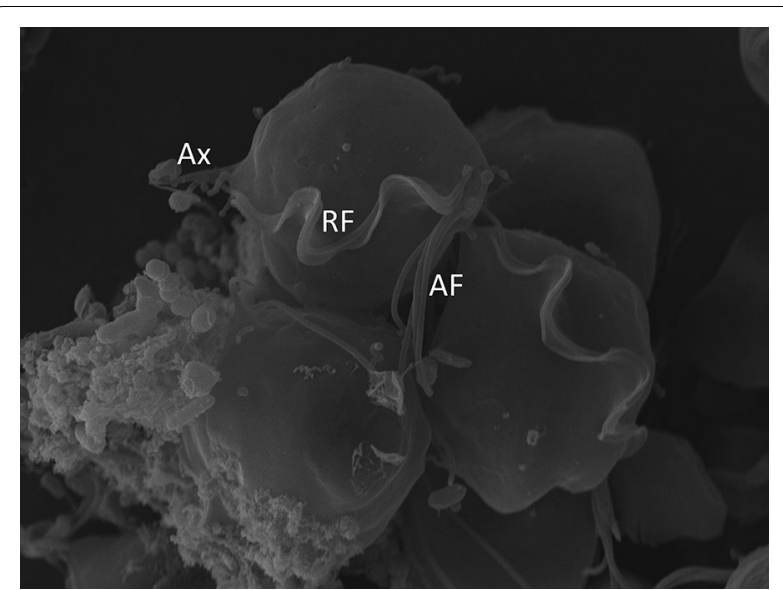

Fig. 2 Scanning electron microscopy of the trophozoites of Trichomonas tenax isolated from the gingival pocket in a xenic culture. Note the four anterior flagella (AF), recurrent flagellum (RF) and the undulating membrane, axostyle (Ax)
Felleisen [9]. PCR products of approximately $370 \mathrm{bp}$ were obtained from both samples (cystic content and gingival packet).

The DNA sequence was determined directly from the PCR products on both strands using the same primers employed for PCR at a DNA sequencing core facility (Genomed S.A., Warsaw, Poland). The obtained sequences were analysed using the Basic Local Alignment Search Tool program (BLASTn) and compared with those deposited at GenBank. The 368 bp fragment showed complete shared identity $(100 \%)$ with a sequence of T. tenax (strain-Hs-4:NIH,USA; ATCC 30207) with accession No. U86615.1

The owner decided not to bear the costs of treatment and the dog was euthanized by the wish of the owner. The dog was not necropsied.

\section{Conclusions}

The most common salivary gland diseases in dogs are mucocele, sialocele and sialadenitis [14-16]. The underlying cause is often not established, but these conditions may be caused by blunt trauma, foreign bodies, sialoliths, autoimmune diseases or neoplasia. Canine sialadenitis has most often been related to bacterial invasions from the oral cavity as a secondary event to gingivitis/paradontosis or to specific viral diseases such as distemper or rabies [17, 18]. A parasitic aetiology of salivary disorders in dogs is uncommon; however, according to van der Merwe et al. [19] canine spirocercosis occurs frequently in dogs with salivary gland enlargement. The present study is apparently the first report of infestation of the salivary glands by T. tenax in a dog.

Trichomonas tenax is considered specific to humans and knowledge on its zoonotic potential is limited [20]. However, the isolation of T. tenax from various domestic animals such as dogs, cats and horses sheds new light on its narrow specificity and host range $[6,8]$. Opinions about the pathogenicity of $T$. tenax are divided. It is frequently found in humans with poor oral hygiene and in individuals with advanced stages of periodontal disease [21]. A significant correlation between the occurrence of T. tenax and periodontal diseases has been demonstrated in dogs [8]; however, the roles of T. tenax in canine periodontal disease is still not fully understood. Proteolytic and collagenolytic activities as well as cytotoxicity abilities of T. tenax were observed in in vitro studies, the results suggest, that this organism should be considered more as parasite than a commensal of oral cavity [22].

Although, T. tenax has a tropism for the oral cavity, infections in other locations such as salivary glands [23], lymph nodes [24] and upper and lower respiratory tracts [25-28] have been reported. Such infections usually tend to be associated with concurrent diseases or with 
immunosuppression due to long-term corticosteroid therapy. In the present case, the only additional condition seen was a chronic periodontitis and it is likely that the infestation of a mandibular gland by $T$. tenax was secondary to the oral infection with T. tenax found in gingival pockets. Because of the relatively high prevalence of trichomonads in dogs with periodontal diseases, these parasites should be considered as a potential aetiological agent in salivary gland infections, especially in individuals with poor oral hygiene.

\section{Authors' contributions}

KS was responsible for the clinical management of the cases. At-S and BL coordinated the ultrasonographic and radiological examinations. KS and ZA organised all sampling and coordinated the laboratory work. KS made the initial diagnosis based on light microscopy examination. KS and KT coordinated the trichomonads cultures and molecular identification of the parasite species. TS performed the scanning electron microscopy examinations. The manuscript was drafted by KS and KT, and finalized jointly by all authors. All authors read and approved the final manuscript.

\section{Author details}

1 Department of Parasitology and Invasive Diseases, Faculty of Veterinary Medicine, University of Life Sciences in Lublin, at Ul. Akademicka 12, 20-033 Lublin, Poland. ${ }^{2}$ Department and Clinic of Animal Surgery, Laboratory for Radiology and Ultrasonography, Faculty of Veterinary Medicine, University of Life Sciences in Lublin, at Ul. Głeboka 30, 20-612 Lublin, Poland. ${ }^{3}$ Interdisciplinary Research Center, John Paul II Catholic University of Lublin, at Al. Kraśnicka 102, 29-718 Lublin, Poland.

\section{Competing interests}

The authors declare that they have no competing interests.

Received: 9 October 2015 Accepted: 11 February 2016

Published online: 18 February 2016

\section{References}

1. Bondurant $\mathrm{RH}$, Honigberg BM. Trichomonads of veterinary importance. In: Kreier JP, editor. Parasitic Protozoa. New York: Academic Press; 1994. p. 111-204.

2. Honigberg BM. Trichomonads Found Outside the Urogenital Tract of Humans. In: Honigberg BM, editor. Trichomonads Parasitic in Humans. New York: Springer-Verlag; 1990. p. 342-93.

3. Hegner RW, Ratcliffe H. Trichomonads from the mouth of the dog. J Parasitol. 1927;14:51-3.

4. Beelitz P, Schöl H, Cothe R. Trichomonaden-Infektionen der Mundhöhle bei Hunden. Kleintierpraxis. 1992:37:281-2.

5. Breuker S. Untersuchungen über Trichomonaden bei Rüden mit Prostataveränderungen. PhD thesis, Justus-Liebig-Universitaet, Gießen.1995. https://bib.vetmed.fu-berlin.de/ResourceList/details/64602.

6. Cielecka D, Borsuk P, Grytner-Ziecina B, Turkowicz M. First detection of Trichomonas tenax in dog and cat by PCR-RFLP. Acta Parasitol. 2000;4:350-2

7. Kutisova K, Kulda J, Cepicka I, Flegr J, Koudela B, Teras J, Tachezy J. Tetratrichomonads from the oral cavity and respiratory tract of humans. Parasitology. 2005;131:309-19.
8. Szczepaniak K. Morphometric, biochemical and molecular characterization of trichomonads isolated from dogs and cats with stomatitis. PhD thesis, University of Life Sciences in Lublin, Lublin. 2013. https://www. researchgate.net/publication/282335959_Morphometric_biochemical_and_molecular_characterization_of_trichomonads_isolated_from_ dogs_and_cats_with_stomatitis. doi: 10,13140/RG.2.1.3011.1209.

9. Felleisen RS. Comparative sequence analysis of 5.8S rRNA genes and internal transcribed spacer (ITS) regions of trichomonadid protozoa. Parasitology. 1997;115:111-9.

10. Amin A, Bilic I, Berger E, Hess M. Trichomonas gallinae, in comparison to Tetratrichomonas gallinarum, induces distinctive cytopathogenic effects in tissue cultures. Vet Parasitol. 2012;25:196-206.

11. Diamond LS. The establishment of various trichomonads of animals and men in Axenic culture. J Parasitol. 1957;56:79-81.

12. Mehlhorn $\mathrm{H}, \mathrm{Al}$-Quraishy S, Aziza A, Hess M. Fine structure of the bird parasites Trichomonas gallinae and Tetratrichomonas gallinarum from cultures. Parasitol Res. 2009;105:751-6. doi:10.1007/s00436-009-1451-8.

13. Ertabaklar H, Caner A, Döşkaya M, Demirtaş LO, Töz SO, Ertuğ S, Gürüz Y. Comparison of polymerase chain reaction with wet mount and culture methods for the diagnosis of trichomoniasis. Turkiye Parazitol Derg. 2011;35:1-5.

14. Mahmoud MS, Rahman GA. Pulmonary trichomoniasis: improved diagnosis by using polymerase chain reaction targeting Trichomonas tenax $18 \mathrm{~S}$ rRNA gene in sputum specimens. J Egypt Soc Parasitol. 2004:34:197-211.

15. Smith MM. Oral and salivary gland disorders. In: Ettinger SJ, Feldman EC, editors. Textbook of Veterinary Internal Medicine. 6th ed. St. Louis: Elsevier Saunders; 2004. p. 1295-7.

16. Spangler WL, Culbertson MR. Salivary gland disease in dogs and cats: 245 cases (1985-1988). J Am Vet Med Assoc. 1991;198:465-9.

17. Brown CC, Baker DC, Barker IK. Alimentary system. In: Jubb KVF, Kennedy PC, Palmer N, editors. Pathology of Domestic Animals, vol. 2. 5th ed. St. Louis: Elsevier Saunders; 2007. p. 32-5.

18. Boonsriroj H, Manalo DL, Kimitsuki K, Sihmatsu T, Shiwa N, Shinozaki $\mathrm{H}$, Takahashi Y, Tanaka N, Inoue S, Park CH. A pathological study of the salivary glands of rabid dogs in the Philippines. J Vet Med Sci. 2015. [Epub ahead of print]. doi: 10.1292/jvms.15-0308.

19. van der Merwe LL, Christie J, Clift SJ, Dvir E. Salivary gland enlargement and sialorrhoea in dogs with spirocercosis: a retrospective and prospective study of 298 cases. J S Afr Vet Assoc. 2012;83:920.

20. Maritz JM, Land KM, Carlton JM, Hirt RP. What is the importance of zoonotic trichomonads for human health? Trends Parasitol. 2014;30:333-41.

21. Kurnatowska AJ, Dudko A, Kurnatowski P. Invasion of Trichomonas tenax in patients with periodontal diseases. Wiad Parazytol. 2004;3:397-403.

22. Ribeiro LC, Santos C, Benchimol M. Is Trichomonas tenax a parasite or a commensal? Protist. 2015;166:196-210.

23. Duboucher C, Mogenet M, Périé G. Salivary trichomoniasis. A case repor of infestation of a submaxillary gland by Trichomonas tenax. Arch Pathol Lab Med. 1995;119:277-9.

24. Duboucher C, Farto-Bensasson F, Chéron M, Peltier JY, Beaufils F, Périé G. Lymph node infection by Trichomonas tenax: report of a case with coinfection by Mycobacterium tuberculosis. Hum Pathol. 2000;31:1317-21.

25. Chiche L, Donati S, Corno G, Benoit S, Granier I, Chouraki M, Arnal JM, Durand-Gasselin J. Trichomonas tenax in pulmonary and pleural diseases. Presse Med. 2005:34:1371-2.

26. Duboucher C, Caby S, Chabé M, Gantois N, Delgado-Viscogliosi P, Pierce R, Capron M, Dei-Cas E, Viscogliosi E. Human pulmonary trichomonoses. Presse Med. 2007;36:835-9.

27. Hersh SM. Pulmonary trichomoniasis and Trichomonas tenax. J Med Microbiol. 1985;20:1-10.

28. El Kamel A, Rouetbi N, Chakroun M, Battikh M. Pulmonary eosinophilia due to Trichomonas tenax. Thorax. 1996:51:554-5. 